Mini Review

\title{
The preventive role of breast self-examination was sponsored by family doctors: historical review
}

\begin{abstract}
Breast self-examination is presumed to be a modern innovation. However, the old literature contained considerable evidence of its practice. Moreover, the role of family doctors in this field stood out for notice. And so do some lessons derivable there from nowadays.
\end{abstract}

Keywords: breast-self-examination, history, family doctor, target therapy
Volume 3 Issue 5 - 2015

\author{
Wilson Onuigbo \\ Department of Pathology, Medical Foundation and Clinic, \\ Nigeria \\ Correspondence: Wilson Onuigbo, Department of Pathology, \\ Medical Foundation and Clinic, 8 Nsukka Lane, Enugu 40000I, \\ Nigeria, Tel 2.35E+12, Email wilson.onuigbo@gmail.com
}

Received: October 30, 2015 | Published: December 07, 2015

\section{Introduction}

As was documented recently, breast self-examination (BSE) is a very important preventive measure. ${ }^{1}$ Incidentally, it is thought to be a modern innovation. Thus, Eggertsen et al. ${ }^{2}$ dated its early history to the late 1940s. However, a search of the old literature reveals that it had been known for well over a century. It is important, therefore, to provide some data not only on its long historical origins with particular reference to recognizing the role of family doctors but also on the lessons derivable from such knowledge.

\section{Historical origins}

The concept of self-examination of the breast was already so important that Young ${ }^{3}$ directed particular attention "to the diseased formations so frequent in the breast of women." Indeed, as he put it, "the female world cannot be too earnestly informed of the danger which attends them; and of the serious urgency of promptly disclosing their slightest apprehensions of any such formations taking place ..." Accordingly, that old master stressed on not only the great need for informing the women concerning this lesion but also on the promptness for disclosing its presence to their family doctors. Doctors in family practice also came up for specific mention elsewhere that same year. Thus, Home $\mathrm{E}^{4}$ emphasized the menace of breast cancer and the need for it to be "made familiar to the minds of those who are liable to the disease, as well as to their medical attendants". Attendants of note were specifically mentioned to be the family doctors by Glaister ${ }^{5}$ of Glasgow. In particular, concerning early operation, he advised as follows: "You must take along with you as a very important aid in this, the services of the family doctor." Similarly, Billroth ${ }^{6}$ was strongly of the opinion that "we should get much better results if the general practitioner, to whom these tumours are first made known, would earlier and stringently insist on an operation." Operation of the urgent type was recommended to the women at risk by Henry, ${ }^{7}$ the English translator of a French treatise on the breast. He exemplified this with an illustrative case which occurred in 1846: "Influenced by the example of what had fallen other members of her family, who had suffered from cancer, she determined to have the swelling which she had discovered, taken away with as little delay as possible." Possible participation of the patient in the observation process was repeatedly apparent in the report of Gould. ${ }^{8}$ The woman was a nurse. She noticed a small lump in the left breast in 1888. This slowly enlarged and the breast was excised in May 1890. Again, in July 1892, she noticed a lump in the adjacent armpit and returned to the hospital for its removal. Furthermore, in February 1894, the patient noticed some lumps near the scar of the first operation as well as a lump above the right breast, and all the nodules were extirpated. Indeed, it transpired ultimately that her cancer regressed even after she sustained fractures! Elsewhere, this case was included in a historical review of cancer regression dating back to $1753 .^{9}$

\section{Historical lessons}

From the old literature, it is apparent that there have been innate problems regarding BSE. Perhaps, present efforts in promoting BSE will gain from the past with special reference to the preventive lessons which can be learnt from the literature.

Firstly, there has been ingrained modesty about the breast. For instance, Bell1 ${ }^{10}$ was aware that it often happened that, "from an improper delicacy in patients," they hesitated to divulge their findings early. Indeed, Young ${ }^{2}$ lamented about it, calling it "all the delusive considerations of a false delicacy." How far, we may ask, do such inhibitions still hold sway today? Secondly, there is a hide-and-seek atmosphere in breast cancer consultations. I believe that the great Sir Cooper ${ }^{11}$ was conversant with it as can be seen from my italicized parenthesis in his following statement. "The first symptom of scirrhous breast," he opined, "is the discovery (as the patient says, by accident) of a hard and moveable swelling..." In the case of a servant girl managed by Bryant, ${ }^{12}$ "a lump was accidentally discovered by a fellow-servant in the patient's right breast." Therefore, is the accident label but an evidence of procrastination? Thirdly, there is the misconception of expecting pain before considering breast masses to be serious. Thus, concerning the above servant-girl, we learn that "It gave her no pain or inconvenience; consequently she did not seek advice for it until about eighteen months." Incidentally, Hutchinson ${ }^{13}$ recognized this problem himself.

Fourthly, the associated pain may be denied. This took place in the case of a man ill with breast cancer. According to the report of Milton. ${ }^{14}$ "He told me it gave him no pain but his wife always maintained that he used to complain at this time of dull aching pain." Lastly, the patient had to brave the prevailing operative maneuvers. In this context, very long ago, Norford ${ }^{15}$ took the trouble to oppose 
the gloomy picture painted in those days by no less an authority than the great Monro of Edinburgh. Little wonder that, in order to combat such orthodox ominous opinions, he wrote with conviction thus: "I would evince the necessity of the patients applying early in cancerous cases, if they expect to find any lasting benefit by the surgeon's skill." Skill in surgery itself was alas not enough. Indeed, it was a great yoke for the patient to carry, leading to concealment of the results of BSE. Apparently, patients failed to come forward because "they dread the horrors of incision". ${ }^{3}$ For example, one of them was "so much afraid of the cutting" that she did not consent to the proposed operation. ${ }^{12}$ Similarly, another patient "was frightened for more cutting" and so allowed the disease to reach the stage of her "suffering all the miseries of cancer that cannot be taken away". ${ }^{15}$

\section{Conclusion}

In summary, both patients and practitioners had long known about self-examination of the breast. Unfortunately, concealment and procrastination tended to occur largely because of the dreaded surgical mode of treatment in vogue. Is there any doubt that, if the cure of breast cancer could rest on just potent pills, self-examination of this organ and its reportage would readily be practiced? After all, the history of tuberculosis was in this calamitous category until its chemotherapy became readily assured. ${ }^{16}$ Perhaps, gloom will change to bloom if my hypothesis ${ }^{17}$ on the existence of a hitherto hidden Natural Factor of defence present in the human thoracic duct is not only recognized but also replicated in translational laboratories in the developed countries. Accordingly, in all probability, tangible target therapy concerning cruel cancer could benefit suffering mankind sooner than later.

\section{Acknowledgements}

None.

\section{Conflicts of interest}

The authors declare that there is no conflict of interest.

\section{References}

1. Al-Naggar, Bobryshev, Al-Jashamy. Practice of breast self-examination among women in Malaysia. Asian Pac J Cancer Prev. 2012;13(8):38293833 .
2. Eggertsen SC, Bergman JJ. Breast self-examination: historical perspectives and current progress. J Fam Pract. 1983;16(4):713-716.

3. Young S. An inquiry into the nature and action of cancer: with a view to the establishment of a regular mode of curing that disease by natural separation. R Phillips, London, UK. 1805.

4. Home E. Observations in surgery, illustrated with cases. Cadell, London. 1805:254-260.

5. Glaister J. Cancer from the family practitioner's point of view. Trans Glas Pathol Clin Soc. 1886;2:279.

6. Billroth T. Lectures on surgical pathology and therapeutics. London, UK. New Sydenham Society; 1878:2:494.

7. Velpeau A. A treatise on the diseases of the breast and mammary region. London, UK. New Sydenham Society; 1856:487.

8. Gould AP. A case of spontaneous disappearance of secondary cancerous growths. Trans Clin Soc Lond. 1897;30:205-208.

9. Onuigbo WI. Spontaneous regression of breast carcinoma: review of English publications from 1753 to 1897. Oncol Rev. 2012;6(2):e22.

10. Bell B. A system of surgery. Charles Elliott, Edinburgh, UK. 1784:2:439.

11. Cooper A. Lectures on diseases of the breast. Lancet. 1824;2:704-725.

12. Bryant T. Very large cysto-sacormatous tumour of the breast. Lancet. $1861 ; 2: 111$.

13. Hutchinson J. On the local origin of cancer. Med Times Gaz. 1881;1:9596.

14. Milton JL. On scirrhus of the male breast. Med-Chir Trans. 1857;40:141156.

15. Norford W. An essay on the general method of treating cancerous tumors. BiblioLife, USA. 1753:33-38.

16. Warpring L. A brief history of tuberculosis. Connecticut Med. 1981;45:177-185.

17. Onuigbo WIB. Nature's necrosis factor when associated with erythrocytes may not only explain the surprises in lung cancer metastasis but also suggest target therapy. Med Hypotheses. 2013;80(6): 698-700. 